\title{
Design Occupant Groups Concept Applied to Fire Safety Engineering Human Behaviour Studies
}

\author{
Mahmut B. N. Horasan \\ Scientific Services Laboratory, \\ 177 Salmon Street, Port Melbourne, VIC 3207 \\ Melbourne, Australia \\ email: mahmut.horasan@agal.gov.au
}

\begin{abstract}
In a similar manner to other fire safety engineering guidelines around the world, the Australian Fire Engineering Guidelines identifies ASET/RSET timeline analysis as one of the methods to be used in assessments. RSET, the occupant related component of this method, can be extremely complicated due to the number of occupants within a building, variations in their characteristics and the unpredictibility of their behaviour. In order to simplify the assessment of occupants, a "design occupant groups" concept is introduced in the, soon to be published, new edition of the Australian Fire Safety Engineering Guidelines. By concentrating only on the occupants that are likely to have a major impact on various phases of the evacuation process design occupant groups approach aims to limit uncertainties and the scope for error. When combined with a quasi-probabilistic variation of the traditional ASET/RSET assessment, the design occupant groups approach has the potential to generate more reliable outcomes with less inherent risk (or conservatism).
\end{abstract}

\section{Keywords}

evacuation, occupant groups, RSET

\section{Introduction}

"Winwood Reade is good upon the subject," said Holmes. "He remarks that, while the individual man is an insoluble puzzle, in the aggregate he becomes a mathematical certainty. You can, for example, never foretell what any one man will do, but you can say with precision what an average number will be up to. Individuals vary, but percentages remain constant. So says the statistician."

From "The Sign of Four", Sir Arthur Conan Doyle. (Chapter 10, The End of the Islander)

In countries which have adopted performance based regulations, the main objective of Fire Safety Engineering (FSE) assessments are to assess compliance with the performance requirements of the Building Codes and/or regulations. 
The procedures to be adopted and applied during fire safety engineering assessments are provided in miscellaneous documents. In Australia the procedures, relevant methodologies and some data are defined and described in a document titled "Fire Safety Engineering Guidelines" (FSEG) [1].

Among the evaluation methods which are described in the FSEG and also adopted globally is the timeline approach. Timeline assessments are mostly designated as Available Safe Egress Time (ASET)/Required Safe Egress Time (RSET) evaluations. Despite its limitations this is an approach globally accepted as being suitable for performance based engineering assessments especially in the context of performance based codes.

The two components of an ASET/RSET evaluation relate to the fire and the people. The assessment is based on the simple premise that the occupants should leave a building or a part of a building before the unset of untenable conditions. The fire generates the products such as heat and smoke which would lead to untenability. ASET is obtained by evaluating a number of fire scenarios and design fires. RSET is a function of occupants.

Notwithstanding its popularity, a number of major problems have been identified in relation to this method of evaluation both by practicing fire safety engineers and fire safety science researchers.

One of the problems at the core of an ASET/RSET evaluation is that it requires definite time values as input. When it comes to human behaviour it is not always possible to provide this data. Human behaviour is:

- extremely complex,

- highly unpredictable,

- affected by many factors and variables.

When we combine the issue of unpredictibility of individuals with the sometimes extremely high population numbers within an occupancy, the problem faced by fire safety engineers becomes almost unresolvable.

However, the same complexity is faced when fires are analysed. In fire modelling a large variety of fires may occur within a particular building and enclosure due to varying ignition sources, fire loads and environmental conditions. To simplify the assessment a particular fire is usually selected as being the most likely and credible one and it is adopted as a "design fire" [2].

In order to carry out fire safety engineering assessments effectively it is obvious that certain levels of simplification also need to be introduced to the people aspect of the assessment. The Australian Fire Safety Engineering Guidelines attempts this by introducing the concept of "Design Occupant Groups". 
Most occupancies which are subject to fire safety engineering assessments would contain a diverse range of occupants. Ideally each individual occupant should be taken into consideration during an assessment. However, the level of detail required for the assessment would make it extremely complex and difficult to control. The positive impact of such detail on the accuracy of the overall outcome is also disputable.

While individuals may get involved in specific or even unique behaviour, research on and observations of human behaviour in fire clearly indicate that it is particular groups of occupants that play a major role and control the whole or stages of the evacuation process. Hence, by concentrating on these occupant groups the whole process may be simplified.

An approach where the large number of occupant groups are reduced to a critical few could lead to:

- the simplification of the assessment,

- the reduction of the number and magnitude of uncertainties (by eliminating some of the sources), and

- the attainment of a more reliable outcome with satisfactory levels of conservatism.

The most common and/or dominant (in the context of their impact on evacuation process not the number of individuals in the group) occupant groups are identified and the FSE analysis is based on these groups. Similar to the selection of "design fires" for fire modelling. the selected occupant groups are referred to as "design occupant groups".

It is likely that there will be more than one design occupant group for an occupancy and each design occupant group may play a dominant role at a different stage of the evacuation process. The three stages of evacuation are commonly identified as detection, pre-movement and movement. While in some occupancies a single group may control all three stages, in others a certain group may control the detection and pre-movement stages and another the movement stage. There may even be situations where each of the stages are controlled by a separate design occupant group.

Some governing characteristics that may be considered in identifying occupant groups present in an occupancy are listed in Table 1. To avoid excessive complexity only the most critical, relevant or significant characteristics should be considered for a given group. The decision as to which characteristics need to be considered may be based on the literature, engineering judgement or discussions between all interested parties. 
Table 1 Dominant characteristics that may be considered in identifying design occupant groups

\begin{tabular}{|c|c|}
\hline $\begin{array}{ll} & \text { Characteristics } \\
\text { Distribution }\end{array}$ & $\begin{array}{ll} & \text { Examples } \\
\text { - } & \text { Number } \\
\text { - } & \text { Gender } \\
\text { - } & \text { Age } \\
\text { - } & \text { Location }\end{array}$ \\
\hline State & $\begin{array}{ll}\text { - } & \text { Awake/asleep } \\
\text { - } & \text { Intoxicated/sober } \\
\text { - } & \text { Unconscious/fully conscious } \\
\end{array}$ \\
\hline Physical attributes & $\begin{array}{ll}\text { - } & \text { Mobility } \\
\text { - } & \text { Speed of travel } \\
\text { - } & \text { Hearing ability } \\
\text { - } & \text { Visual ability } \\
\end{array}$ \\
\hline Mental attributes & $\begin{array}{ll}\text { - } & \text { Level of understanding } \\
\text { - } & \text { Potential emergency behaviour } \\
\text { - } & \text { Ability to take and implement } \\
& \text { decisions independently }\end{array}$ \\
\hline Level of assistance required & $\begin{array}{l}\text { Requires full assistance/requires } \\
\text { some assistance/does not require } \\
\text { assistance } \\
\end{array}$ \\
\hline Emergency training & $\begin{array}{l}\text { - } \quad \text { Trained/untrained } \\
\text { - } \quad \text { Warden/occupant } \\
\end{array}$ \\
\hline Occupant (group) roles & $\begin{array}{ll}\text { - } & \text { Parent/child } \\
\text { - } & \text { Teacher/student } \\
\text { - } & \text { Nurse/patient } \\
\text { - } & \text { Staff / customer }\end{array}$ \\
\hline Activity at the outbreak of fire & $\begin{array}{ll}\text { - } & \text { Working in a noisy environment } \\
\text { - } & \text { Watching a performance } \\
\end{array}$ \\
\hline Familiarity with the building & $\begin{array}{l}\text { - Unfamiliar/relatively } \\
\text { familiar/familiar }\end{array}$ \\
\hline
\end{tabular}

Once all occupant groups and their characteristics are identified, design occupant groups may be established.

Occupant numbers should not be the main criteria in the selection of the design occupant groups. If any of the occupant groups have characteristics which would influence the outcome of a fire scenario they should be identified as a "design occupant group" (eg. elderly people). In some cases, the design occupant group may consist of only one person (eg. a highly trained fire warden) where as in others there may be thousands of people in a design occupant group (eg. spectators in a stadium). 
The fire engineering assessment should identify the design occupant group or groups to be adopted for the analysis and, if appropriate, describe which group will be used in each step of the analysis of the evacuation process.

Table 2 provides some candidate design occupant groups for different occupancies. It must be remembered that design occupant group selection can be subjective and always is scenario dependent. In some occupancies there will be a number of design occupant groups. It will be up to the fire safety engineer(s) to decide which of the occupant groups is the most appropriate one for the scenario being investigated. For example, in a classroom when a teacher is present the detection and pre -movement times would most likely be dictated by the teacher. However, in the absence of a teacher the students become the detection and pre-movement subgroup [3].

Table 2 Design occupant groups for different occupancies

\begin{tabular}{|l|l|l|l|}
\hline \multicolumn{1}{|c|}{ Occupancy } & \multicolumn{1}{|c|}{ Detection } & Pre-movement & \multicolumn{1}{|c|}{ Movement } \\
\hline Shopping Centre & $\begin{array}{l}\text { Management/Staff/ } \\
\text { Public }\end{array}$ & Wardens / Public & Public \\
\hline $\begin{array}{l}\text { Hotel (room of fire } \\
\text { origin) }\end{array}$ & Guest & Guest & Guest \\
\hline Hotel (other rooms) & Management & $\begin{array}{l}\text { Management / } \\
\text { Guests }\end{array}$ & Guests \\
\hline School & $\begin{array}{l}\text { Students / } \\
\text { Administration }\end{array}$ & $\begin{array}{l}\text { Students / } \\
\text { Administration }\end{array}$ & Students \\
\hline $\begin{array}{l}\text { Residential Apartment } \\
\text { Building (apartments } \\
\text { other than that of Fire } \\
\text { Origin) }\end{array}$ & Residents & Residents & Residents \\
\hline Hospital & Hospital Staff & Hospital Staff & Patients \\
\hline
\end{tabular}

To elaborate on the hospital example. In a hospital the staff, patients and the visitors would be the most likely occupant groups . For the assessment of a fire occurring at night, the visitors, may be ignored. At night, the staff will be the dominant group in the detection of the fire and the initiation of evacuation, hence, the staff would be designated as the design occupant group to assess the detection and pre- movement phases. However, it will be the patients that will determine the movement time based on their mobility and they should be the design occupant group for the movement phase. The detection and pre-movement times for the staff occupant group can be adopted as the universal times for the whole or part of a hospital. The time for all patients to move to a place of safety will be determined by the type of patient, eg. intensive care, surgery, etc., and this may vary from ward to ward.

Design occupant groups may be identified in a number of ways. It will be to the benefit of any assessment to adopt a methodical approach in the determination of design occupant groups instead of ad hoc nomination of groups. A systematic methodology to identify design occupant groups is proposed in Figure 1. This by no means is a sophisticated methodology which covers all aspects of design occupant group 
determination. However, when used as a guide, it should provide the fire safety engineers with a simple and logical tool.

In order to better explain the methodology an example demonstrating the establishment of design occupant groups for an international airport terminal building is included.

Once the design occupant groups are established and agreed upon, the next stage is the quantification of each of RSET stages.

PROCESS

1. For the occupancy being assessed, identify occupants who share major traits and attributes, and develop occupant groups.

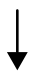

2. Describe and name each occupant group.

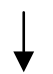

3. Identify building detection and warning

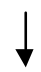

4. For each scenario to be investigated in the FSE assessment, identify the occupant group most likely to play $c$ major role in detection.

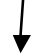

5. For each scenario to be investigated in the FSE assessment, identify the occupant group most likely to play major role in pre-movement.

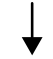

6. For each scenario to be investigated in the FSE assessment, identify the occupant group most likely to play major role in movement based on physical and mental attributes and familiarity with the building.

OUTPUT

EXAMPLE

Essential characteristics to consider:

- Distribution

- Physical attributes

- Mental attributes

- Level of assistance required

- Emergency training

- Occupant (group) roles

- Familiarity with the building

- Local travellers

- Overseas travellers

- People meeting or seeing off travellers

- Airline ground staff

- Airport management

- Airport workers

- Customs officers

- Security personnel

- Automatic detection and and warning

- EWIS

- Advanced PA

- Graphical displays

- Fire cues (smoke smell, smoke sight, flames, etc.)

Design

Occupant

Group for

detection

Design

Occupant

Group for pre-

movement

Design

Occupant

Group for

movement
Airport Management

Security personnel

- Local travellers

- Overseas travellers

- People meeting or seeing off travellers All three combined: Public

Figure 1 - Design Occupant Group Identification Flow Chart incorporating an example based on an international airport terminal building 


\section{RSET Quantification and ASET/RSET Assessments}

RSET quantification is a complicated task. Some components of RSET such as detection (or cue occurrence) times are a function of smoke or fire and there are a number of models which can be adopted to estimate these. Similarly there are a variety of validated people movement time calculation models available for fire safety engineers. The major difficulty relates to the phase between the occurrence of cues and the initiation of movement, which is known as pre-movement. The conventional approach is to allocate some absolute time values in relation to this period. The question is where and how to obtain these definite time values? Allocating some absolute pre-movement times based on observations, research studies or unvalidated methods will generally lead to inappropriate or highly conservative and extended pre-movement times. Fortunately, the majority of the fire safety engineers choose the second option and adopt high levels of conservatism in their pre-movement time estimations [4].

Even within a single design occupant group the individual occupants are likely to have varying characteristics. Hence, there will be many uncertainties in relation to the characteristics and the pre-movement times for a particular design occupant group [5]. As most of the available data on pre-movement times is inconsistent and is spread over a wide range, adopting a probabilistic approach could provide a preferable method for estimating pre-movement times in relation to a design occupant group.

This could lead to a "hybrid" approach where probabilistic pre-movement times are combined with deterministic detection and movement times. The traditional ASET/RSET timeline may be modified as shown on Figure 2 to reflect this approach.

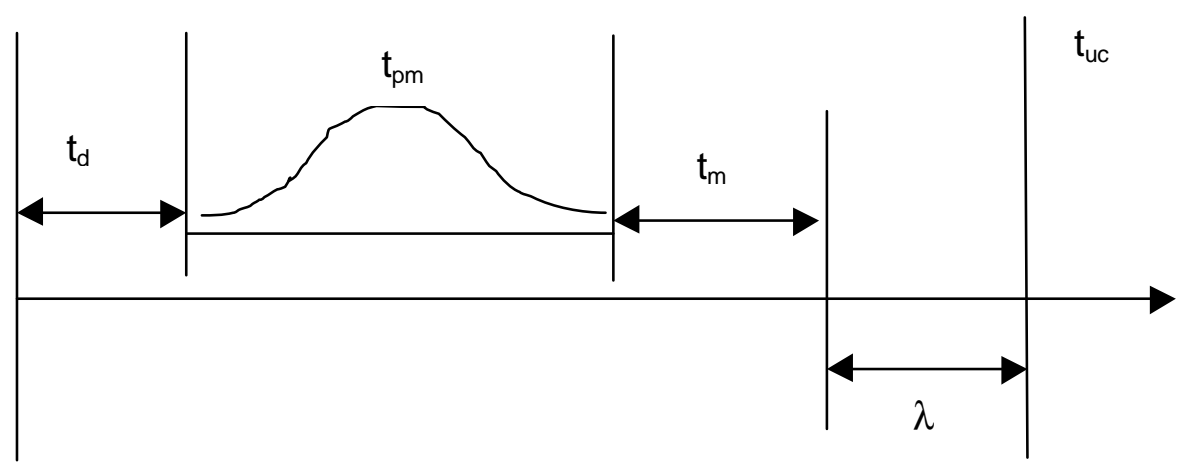

where:

$\begin{array}{ll}t_{\mathrm{d}}: & \text { time to detection / cue occurrence } \\ t_{\mathrm{pm}}: & \text { time to decision to move (pre-movement time) } \\ \mathrm{t}_{\mathrm{m}}: & \text { movement time } \\ \mathrm{t}_{\mathrm{uc}}: & \text { time to untenable conditions } \\ \lambda: & \text { safety margin }\end{array}$

Figure 2 
While there may be some variations for a given scenario, the $t_{d}$ (time to detection) and $t_{m}$ (total movement time) values would be close to being a constant.. Detection is a function of fire and/or the detection systems, and based on the design fire adopted the time to detection would be a fixed time value. Similarly, for a particular design occupant group, building layout and fire scenario, based on a hydraulic movement model, the time to reach to safety would be constant. Hence, the combination of detection and movement times may be identified as a constant "c". Figure 2 may be re-arranged as shown in Figure 3.

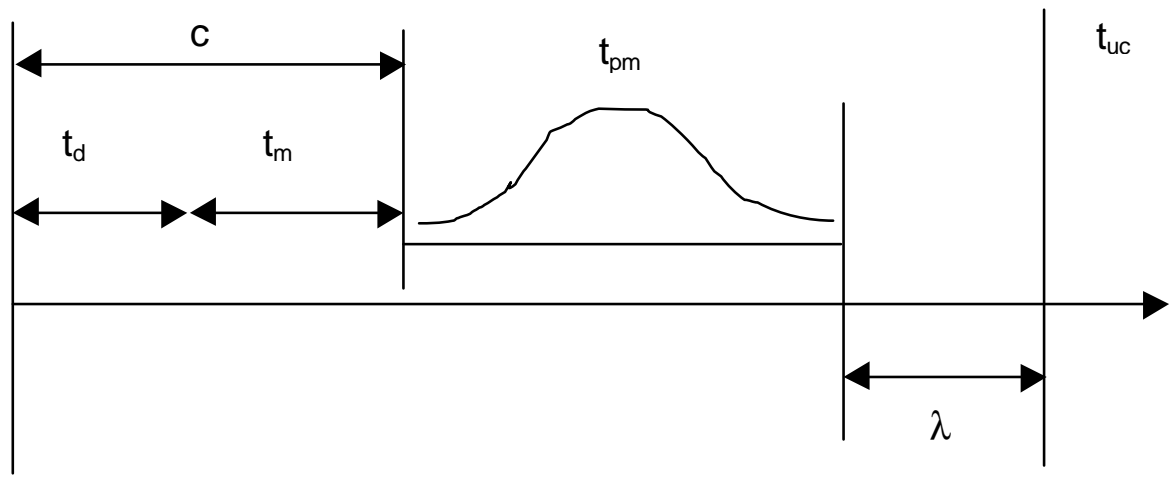

Figure 3

On the other hand, the onset of untenable conditions also incorporates a large number of uncertainties. The tenability criteria is based on smoke layer height, temperature, visibility and toxicity. There is no clear indication of the effect of these criteria on individuals. While 15,000 ppm.min CO may be the tenability limit for a healthy person [6], for a person with respiratory problems the limit may be much lower. Again the visibility of 5 or 10 metres may not be sufficient for persons with vision problems. Therefore, the $\mathrm{t}_{\mathrm{uc}}$ value may also be defined as a probability distribution.

The relation between the individual components of the assessment then may be rearranged as shown in Figure 4.

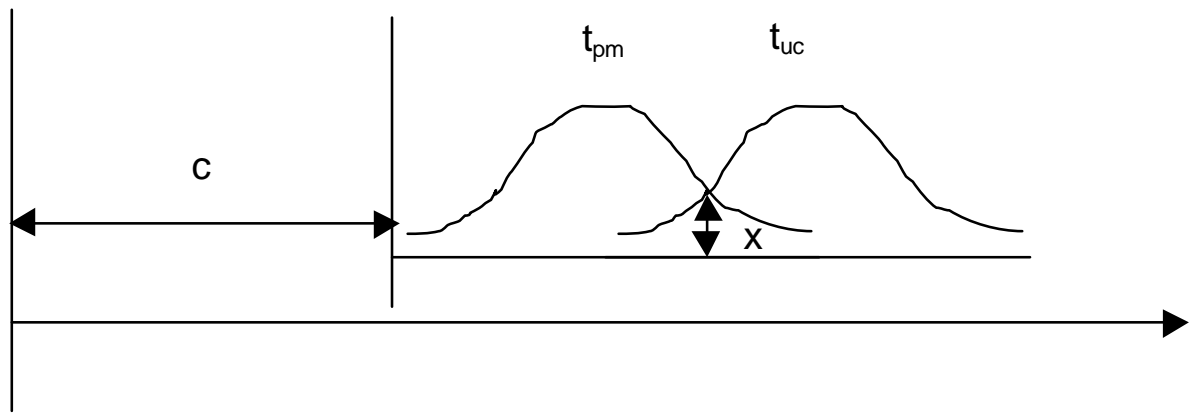

Figure 4 
If the $t_{\mathrm{pm}}$ and $\mathrm{t}_{\mathrm{uc}}$ curves are overlapping it would indicate that there is a probability that untenable conditions may occur before all occupants are able to evacuate the building. The factor "x" in Figure 4 indicates the magnitude of the overlap. Larger the value of "x", larger the number of expected fatalities would be. The goal of the FSE study would be to identify means of minimising "x". This may be achieved by:

- considering alternative trial concept designs which would "move" $t_{u c}$ curve further away from the $t_{e}$ curve,

- $\quad$ using reverse engineering techniques to reduce "c",

- using reverse engineering techniques to alter the distribution of $t_{\mathrm{pm}}$ curve and/or move it away from the $t_{u c}$ curve.

The final solution ideally, should appear as illustrated in Figure 5.

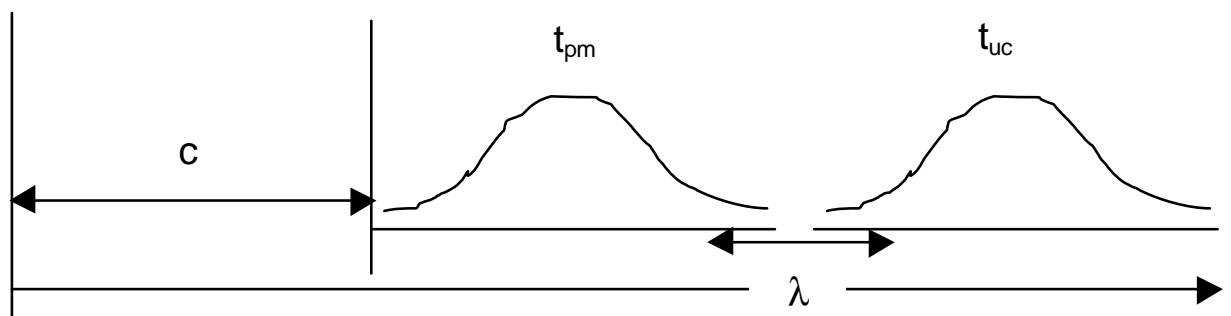

Figure 5

\section{Conclusion}

The issue of reliable and not extremely conservative or risky evacuation evaluations will remain to be biggest problem facing the fire safety engineers for the foreseeable future. Methods adopted are either very simplistic or they heavily rely on expert judgement. While a full probabilistic assessment may provide desirable results, it is still not completely achievable with the present state of the art. Risk assessment models such as FIRECAM [7] or CESARE Risk [8] are limited in their applicability and are not accessible to by majority of the fire safety engineers around the world.

The design occupant group approach presented in this paper simplifies the evacuation assessment by limiting the number of occupant groups to be evaluated within a building. This reduces the scope for errors and misjudgments. It is based on the globally accepted methodology used for identifying and adopting design fires for any given scenario.

The quasi-probabilistic ASET/RSET evaluation discussed is expected improve the reliability of such assessments. 
The existing knowledge does not provide us the pre-movement time probability distributions for different occupancies and/or design occupant groups.

Further research is needed to:

- collect data from literature, real fire incident reports, evacuation drill observations and fire brigade reports towards development of probability distributions

- develop a technique towards the implementation of the mostly probabilistic timeline analysis method described above.

\section{Acknowledgments}

The author would like to acknowledge the contributions of Dr G. Caird Ramsay and the Scientific Services Laboratory team involved in the development of the new edition of the Australian Fire Safety Engineering Guidelines: Dr Peter T. Taylor, Dr Yaping He and Mr Russell Kilmartin.

\section{References}

1 ABCB, Fire Safety Engineering Guidelines, Second Edition, Australian Building Codes Board, Canberra, ACT, Australia, 2001

2 Karlsson, B. and Quintiere, J., Enclosure Fire Dynamics, CRC Press, Boca Raton, 2000.

3 Horasan, M., Bruck, D., "Investigation of A Behavioural Response Model for Fire Emergency Situations in Secondary Schools", 4th International Symposium on Fire Safety Science Proceedings, ISFPA, Maryland USA, , pp 715-726., 1994 Horasan, M, Saunders, W, "Human behaviour research - what information do the fire safety engineers really need?", 2nd Human Behaviour in Fire Symposium, Boston, USA, March, 2001 Brannigan, V., "Human behaviour and risk based fire regulation", 2nd Human Behaviour in Fire Symposium, Boston USA, 2001

6 BSI, "Fire safety engineering in buildings. Part 1. Guide to the application of fire safety engineering principles." DD 240 : Part 1. British Standards Institute, 1997.

7 Beck, V., "Performance Based Fire Engineering Design and its Application in Australia", 5th International Symposium on Fire Safety Science Proceedings, ISFPA, Melbourne Australia, pp 23-40, 1997

8 Yung, D., Hadjisophocleous, G., Proulx, G., "Modelling Concepts for Risk Cost Assessment Model FIRECAM", 5th International Symposium on Fire Safety Science Proceedings, ISFPA, Melbourne Australia, pp 631-642, 1997 